\title{
Making sense of the future: visions and transition pathways of laypeople and professionals from six EU countries
}

\section{E. lacovidou \& W. Wehrmeyer}

To cite this article: E. lacovidou \& W. Wehrmeyer (2014) Making sense of the future: visions and transition pathways of laypeople and professionals from six EU countries, Global Bioethics, 25:4, 211-225, DOI: 10.1080/11287462.2014.957010

To link to this article: https://doi.org/10.1080/11287462.2014.957010

Published online: 23 Sep 2014.

Submit your article to this journal $\pi$

Џll Article views: 363

View Crossmark data $\sqsubset$

Citing articles: 1 View citing articles $\square$ 


\title{
RESEARCH ARTICLE
}

\section{Making sense of the future: visions and transition pathways of laypeople and professionals from six EU countries}

\author{
E. Iacovidou ${ }^{\text {a* }}$ and W. Wehrmeyer ${ }^{\text {b }}$ \\ ${ }^{a}$ Centre for Environmental Policy, Imperial College London, South Kensington Campus, London, UK; \\ ${ }^{b}$ Centre for Environmental Strategy, University of Surrey, Guildford, UK
}

(Received 30 June 2014; accepted 8 August 2014)

\begin{abstract}
In seeking to understand how young people conceptualise their future in terms of sustainability, visioning and backcasting workshops were held in six European countries, as part of the CReating Innovative Sustainability Pathways (CRISP) project. Within the visioning part of the CRISP project, over 1500 ideas and suggestions were generated, which were then condensed into three pan-European archetypical visions: One Ethical World, Local Community and $i$-Tech that exhibit radical alternatives for global and local futures. For the transition pathway development of these futures, backcasting workshops were held with the participation of young people and experts to develop suitable pathways towards each of the three visions with regard to three specific sectors, namely, household energy, individual mobility and food. This paper presents the novel methodology developed and applied in both sets of workshops and describes the innovative approach followed for synthesising strong, coherent transition pathways. The framework of actions of each vision's pathway towards a sustainable, low-carbon Europe is also presented to provide the basis upon which changes towards a sustainable future can be initiated both at structural and practical levels. The paper concludes with an evaluation of the pathways developed by comparing them to the UK 2050 pathways.
\end{abstract}

Keywords: transition; future; visions; backcasting; pathways; framework; actions; laypeople; experts

\section{Introduction}

Unsustainable infrastructure and practices, in their broadest sense, have led to numerous environmental impacts. With this in mind, global and local initiatives have been formed to tackle these environmental impacts by enforcing new regulations, changing infrastructure and making people aware of their actions and associated impacts. These initiatives typically work iteratively and recursively, however, they often share underlying goals that aim at moving towards a better, more sustainable future. These goals have been developed through visions of the future, a future that is sustainable, viable and resourceful, that provides the opportunity to learn through current practices and find ways to change these into more sustainable ones. The goals set by the visions can be achieved via a number of proposed initiatives, which, if put together, can develop a pathway that supports the transition towards a shared vision of the future. The development of transition pathways has been thoroughly studied in the literature, with a number of

\footnotetext{
*Corresponding author. Email: e.iacovidou@imperial.ac.uk
} 
different approaches being demonstrated; the most commonly used approaches are the backcasting methodology and the multi-level framework perspective (Quist, 2007; Smith \& Stirling, 2010).

Backcasting is a process whereby a future end point is defined by stakeholders, who then explore the gap between that future end point and today, and develop objectives and practices to reach that future vision. It was originally introduced in the 1970s by Amory Lovins, as a technique for energy planning called "backwards-looking analysis", but a few years later Robinson proposed the term "backcasting", which has remained until today (Carlsson-Kanyama, Dreborg, Moll, \& Padovan, 2008; Kok, Van Vliet, Bärlund, Dubel, \& Sendzimir, 2011; Mander et al., 2008; Quist \& Vergragt, 2006; Robinson, 1988). The literature covers many studies in which interactive, participatory backcasting is proposed and/or used as a suitable and useful method to explore transition pathways (Carlsson-Kanyama et al., 2008; Quist \& Vergragt, 2006; Rotmans, Kemp, \& van Asselt, 2001; van de Kerkhof \& Wieczorek, 2005). The success of this method lies in its potential to include a broad selection of stakeholders, a variety of visions and a number of participatory and analytical exercises, making it a promising and innovative tool (Quist \& Vergragt, 2006; van de Kerkhof \& Wieczorek, 2005). The selection of visions must be the starting point of backcasting exercises, followed by stepping backwards to the present, where the initiation of discussions is stimulated and oriented to proposing the main steps that need to be taken, the obstacles that must be overcome and the opportunities that should be seized, for the realisation of the selected visions (van de Kerkhof \& Wieczorek, 2005).

Backcasting is also a deliberative process suitable for long-term contexts where the continuation of the past (i.e. forecasting) is perhaps not advisable, desirable or possible (Holmberg, 1998). In addition, some studies highlighted the social implications of participatory backcasting, where developing a shared end point (vision) was found not only to reconcile contradictory or diverging interests of stakeholders very early on (Kok et al., 2011; Robinson, 2003), but participants also felt more positive about the future, which in some cases became "their" future (Carlsson-Kanyama et al., 2008; Chenoweth \& Wehrmeyer, 2006).

One of the studies highlighted that backcasting exercises enable participants to distance themselves from their daily interests and concerns and at the same time make them feel involved in the whole process and aware that their suggestions have an impact on shaping the future (van de Kerkhof \& Wieczorek, 2005). In contrast, Carlsson-Kanyama et al. (2008) suggested that participatory backcasting is devoid of comprehension and completion, due to the lack of participants with varied backgrounds, expertise and values. Moreover, they suggested that for the backcasting process to be successful, an innovative approach must be followed that first enables participants to distance themselves from their concerns and thoughts and become more imaginative, and second allows the development of a plan for realising the visions and establishing the changes that need to be made (Carlsson-Kanyama et al., 2008).

After identifying the challenges posed by the backcasting methodology, Kok et al. (2011) proposed combining backcasting with exploratory scenario development, which provides a useful and comprehensive perspective that allows stakeholders to develop a set of consistent scenarios and gain a better understanding of their future. The combination of backcasting with other methodologies, including forecasting and multi-criteria mapping, has been acknowledged and/or applied by many authors, including Börjeson, Höjer, Dreborg, Ekvall, and Finnvedena (2006), Höjer and Mattsson (2000), Eames and McDowall (2010), Chenoweth and Wehrmeyer (2006) and Mander et al. (2008). This paper will focus on the methodology followed by Eames and McDowall (2010), where participatory backcasting was blended with the multi-level perspective (MLP) so as to include three key themes: regime, niches and landscape. The inclusion of the MLP in their analysis highlights the importance of social, economic, political and technological perspectives when shaping transition pathways. 
The MLP is a recently developed approach that focuses on the analysis of the dynamics of transitions. The term multi-level refers to the interactions between technological niches, sociotechnical regimes and landscapes, which mirror the micro-, meso- and macro-levels of the MLP based on structural, practical and cultural aspects (Foxon, Hammond, \& Pearson, 2010; Geels, 2002, 2006; Lachman, 2013). As a result, transition pathways need to operate in a "3 $\times$ 3" matrix of niches, regions and landscapes reflecting structure, practice and culture over time. In addition, each one of these levels has a broader meaning, particularly the technological niches that provide space where learning occurs and social networks develop that support the generation and development of radical innovations. The social-technical regimes are practices, rules and shared assumptions within which the dominant actors interact with each other and their environment, whereas landscape is the environment (or space) where social, political and cultural values, economy, demography, natural environment and institutions evolve (Foxon et al., 2010; Geels, 2002, 2005; Lachman, 2013; Rotmans et al., 2001). The MLP has been used for the development of transition pathways by many authors (Foxon et al., 2010; Geels, 2002, 2005, 2006; van den Ende \& Kemp, 1999).

When trying to make sense of the future, CReating Innovative Sustainability Pathways (CRISP) - a project supported by the European Commission under the Environment Theme of the 7th Framework Programme for Research and Technological Development involving six countries, namely, the UK, the Netherlands, Norway, Lithuania, Hungary and Greece - used the backcasting approach to develop pathways towards a sustainable and equitable future. The first step was to produce a detailed review of the policy status quo on sustainable development, as well as a practical review of the large number of niche initiatives and projects that could provide insights into low-carbon, sustainable lifestyles by 2030 . Then, to a large extent carried out separately from the policy review, visions of such lifestyles in 2030 were developed, and afterwards backcasting and MLP approaches were used to define the goals and practices necessary in order to enable the development and synthesis of transition pathways towards the defined visions. The innovativeness of this approach lay in the fact that young people were involved in the visioning and backcasting process together with experts. Young people who are going to live in the future, and as CRISP argues, since it is they who will be living in the future, they should have a say in shaping it.

This paper presents the methodology adopted in CRISP for developing the visions and the pathways towards them, with the participation of young people and experts in the visioning and backcasting workshops held in all the countries that participated. It then describes the innovative methodology used for synthesising the pathways and the pathways' frameworks of action, which can be used as a tool for keeping pace with, and ensuring transition to, a sustainable future. Evaluation of the pathways is performed by comparing them to other pathways developed under the same vision/goals. Discussion is then focused on the success of the methodological approach adopted for developing the visions and transition pathways, and the importance of including young people in the process of shaping the future towards more sustainable lifestyles.

\section{Methodology}

The development of pathways towards a sustainable, low-carbon future is a time-consuming process that requires several methodological stages, each involving participation and research, as well as syntheses and analyses of data collected in order to ensure that all aspects have been taken into consideration. Figure 1 illustrates the four initial steps of the development process of the pathways, a further description of which is provided below.

Step 1. Twelve visioning workshops (VWs) were held in each participating country to brainstorm ideas and suggestions for a sustainable future, with an emphasis on three specific sectors: mobility, household energy and food. The VWs predominantly took place at schools and involved 


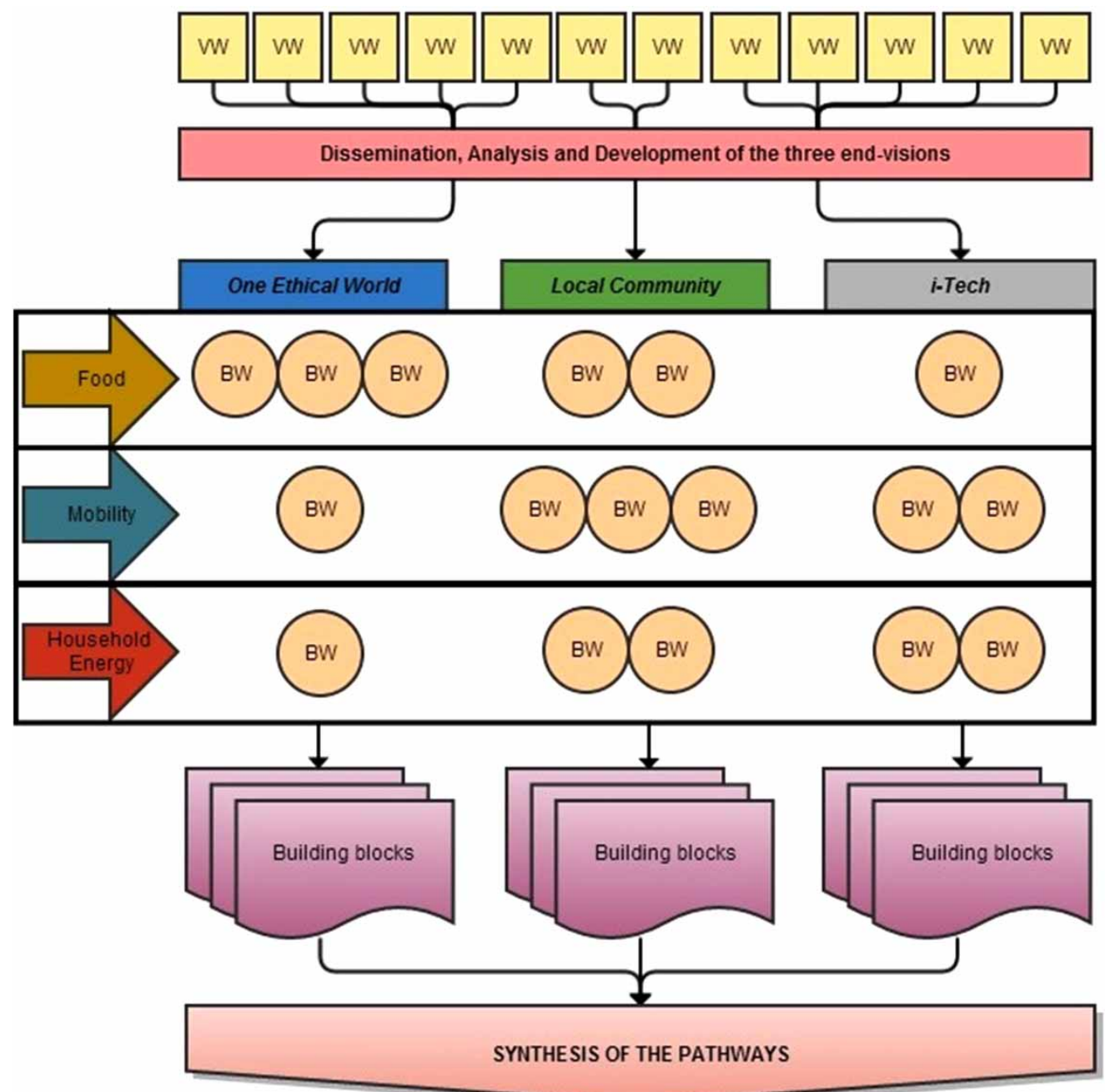

Figure 1. Illustration of the methodology followed for developing the transition pathways towards a sustainable, low-carbon Europe.

teenagers. These pupils were typically in their last year of school, this being seen as a time when pupils are already thinking about their future and possible career options as part of their end of school choices. In each country, workshops were held in both urban and rural settings, involving a range of socio-economic groups, and some schools were more innovative in their teaching philosophies than others.

Step 2. The roughly 1500 ideas produced through the VWs were disseminated and analysed, leading to the development of three end visions, namely, One Ethical World, Local Community and $i$-Tech (Wehrmeyer et al., 2012; Wehrmeyer, Iacovidou, et al., 2013). These visions presented the following broad characteristics:

- One Ethical World: a vision in which globalised supply chains are realised, where global values are interpreted locally, and global health care and governance are envisaged. Fair trade displaces free trade, and social equity is diffused throughout societies. 
- Local Community: a vision of strong regional identity, where local production and consumption are well established, decentralisation is achieved, and vegetarianism, social cohesion, individual responsibility and collaborative consumption become the main features of this sustainable community.

- $i$-Tech: a vision where technology and innovation become the main drivers. The world becomes a highly competitive place and risk is replaced by intelligent machinery. Functional food, renewable energy and efficient high-tech mobility dominate.

Step 3. After the development of the three end visions, 17 backcasting workshops (BWs) were held in all participating countries, which focused on one of the three visions in combination with one of the three sectors, namely, food, household energy and mobility. Building blocks were used to construct the pathways towards one of the vision sectors across a selected timeline, from the year 2013 to 2030. The BWs involved either experts or laypeople, the latter of whom were predominantly students in their last year of school. The reason for mixing the groups within workshops (and not mixing them in one particular workshop) was to allow a better understanding of the different outcomes, the groups and their futures.

Step 4. The building blocks used to develop the vision-sector-specific pathways in the BWs were put together in order to synthesise the selected pathways - one for each vision. This procedure initially followed the MLP, based on Structure, Culture and Practices, in order to attain appropriate and synergistic behaviour. Culture, for example, is considered to affect and be affected by Structure and Practices, but because the ramifications of this effect much depend on history, spatial characteristics, socio-political situations and economic status, no specific actions or concepts were designated to this dimension; not only is it difficult to measure and influence Culture in a deterministic manner, but building blocks have the potential to impact on Culture and in turn to be impacted by Culture. Therefore, it was not possible to attribute any building blocks to Culture as they could equally fit into Structure or Practices. In addition, when engaging practically with the MLP, Structure was found to have a dual dimension with "Governance", and "Infrastructure" to have building blocks that fit in one but often not in the other, making this distinction meaningful and practicable. As a result, the building blocks that made up the 17 pathways were grouped either into Governance and Infrastructure or Practices. In total, over 500 building blocks were identified for all the visions and sectors.

Further on in the pathway development process, the chronological order for the allocation of building blocks carried out in the workshops was separated into four phases: Pre-development, Take-off, Acceleration and Stabilisation, in accordance with the Transition Management (TM) nomenclature (Foxon et al., 2010; Quist \& Vergragt, 2006). Pre-development was a three-year time period, whereas the other three (Take-off, Acceleration and Stabilisation) were four-year time intervals, with 2013 being the base year and 2030 the projection year. Figure 2 is a depiction of the structure of the pathways, where the S-curve represents the timescale of transition, separated into the four phases and the three dimensions which represent the context in which the S-curve evolves.

It was noted that at a given time interval the building blocks of the different pathways contained many common elements that could fit under the same scope. For example, while the building blocks of one of the pathways were aiming to provide political support, to reorient education, to develop new products and production reforms, or to initiate changes in food, transport and energy infrastructural systems, etc., the building blocks of the other pathways, although different from those of the above pathway, were also aiming to provide political support, reorient education, develop new products, etc. This observation led to the development of a structural framework of pathways, presented in Table 1, which identified clusters of homogeneous elements 


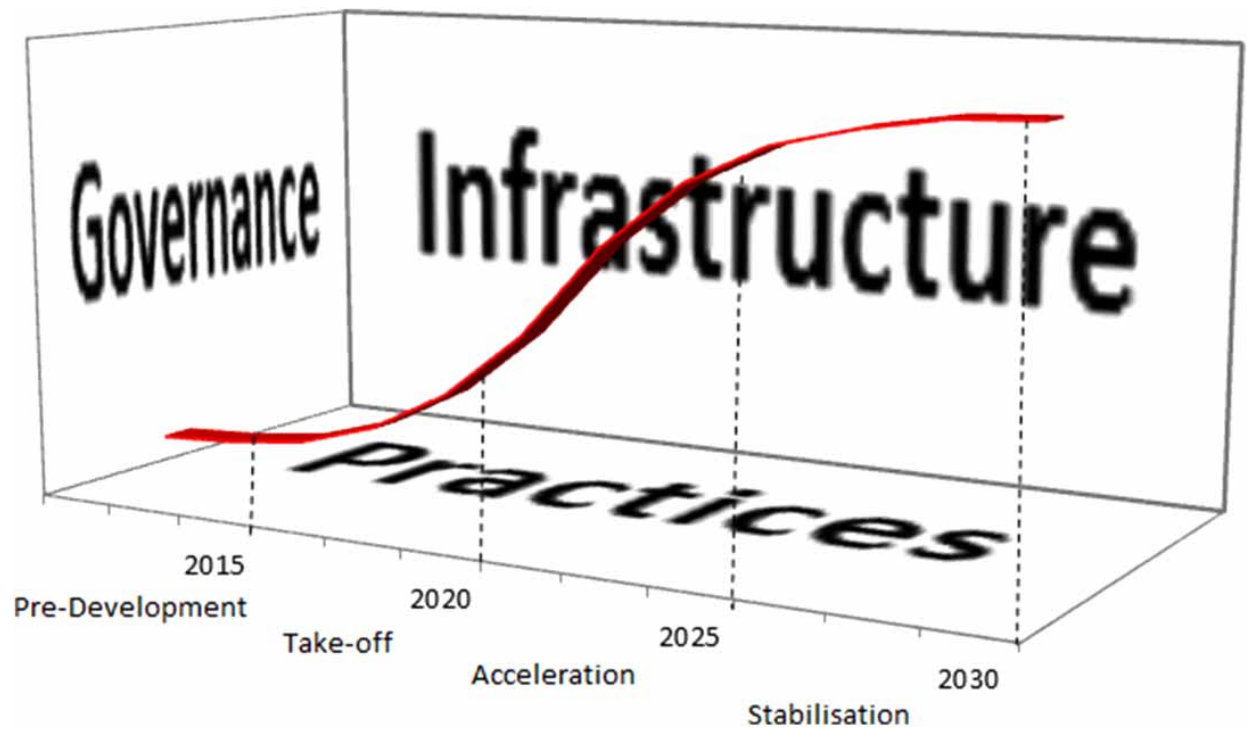

Figure 2. Pathway context and transition phases within three dimensions and the MLP S-curve.

in pathways at specific time intervals and dimensions (e.g. Governance and Infrastructure or Practices).

It should be emphasised that the structural framework is the same for all pathways, which could be said to depict the logic and dynamics of change within this modified TM/MLP perspective. These activities were derived from the BWs in the form of building blocks selected for the development of the pathways. However, the activities enclosed in each cluster of the structural framework often vary

Table 1. Structural framework of pathways based on the clusters identified within each phase and across the three dimensions.

\begin{tabular}{lll}
\hline Governance & Infrastructure & Practices \\
\hline
\end{tabular}

\section{PRE-DEVELOPMENT}

- Political support

- Principles of behaviour

- Support for industry and innovation

- Education

- Strengthening local/global community

TAKE-OFF

- Consolidation and relocation of governance

- Product and production reforms

- Supporting innovation

\section{ACCELERATION}

Consolidation and relocation of budget

\section{STABILISATION}

Completion and assessment of distribution effects
Develop and support:

- Food infrastructure

- Transport infrastructure

- Energy infrastructure

Rolling out of:

- Food infrastructure

- Transport infrastructure

- Energy infrastructure

Acceleration of take-off phase

Integration of food, transport and energy infrastructure
Initiation of changes in:

- Food practices

- Mobility practices

- Energy practices

Rolling out of:

- Food practices

- Mobility practices

- Energy practices

Acceleration of take-off phase

Integration of food, transport and energy practices 
according to sector or vision. In addition, in some clusters, activities were attributed to only one or two pathways, indicating the presence of gaps in the content of some pathways. Gaps were dealt with by adopting one of two approaches: either by retrieving activities identified by the participants during discussion and reflections in the BWs, or by retrieving activities from the list of building blocks that was initially made to be used in the BWs. The latter approach was adopted when there were no, or very few, specific actions attributed to some of the clusters of the pathways developed, and the building blocks from the BWs were not sufficient to fill the gaps.

Nonetheless, both approaches utilised a vast number of actions that were to be implemented for moving towards the future end visions, which were all used to develop a list of actions necessary for the realisation of each vision, for each of the clusters of every pathway. This led to the formation of so-called "To do lists". In total, 24 such lists were compiled for each pathway, the presentation of which, however, is beyond the scope of this paper. These lists in themselves represent end goals, which are considered the key activities of the pathways, and because each cluster is described by a "To do list", it can also be defined by a key activity. Hence, the presentation of all the key activities of each pathway has given rise to the pathway's framework of action. Three frameworks of action were developed, one for each of the three visions' pathways, that is, One Ethical World, Local Community and i-Tech, depicted in Figures 3-5, respectively.

In these frameworks, Acceleration is considered to be an extension of the Take-off phase, primarily because many of the activities required for the pathway to take-off towards the future vision cannot be fully achieved within a five-year period - for example, the development of a

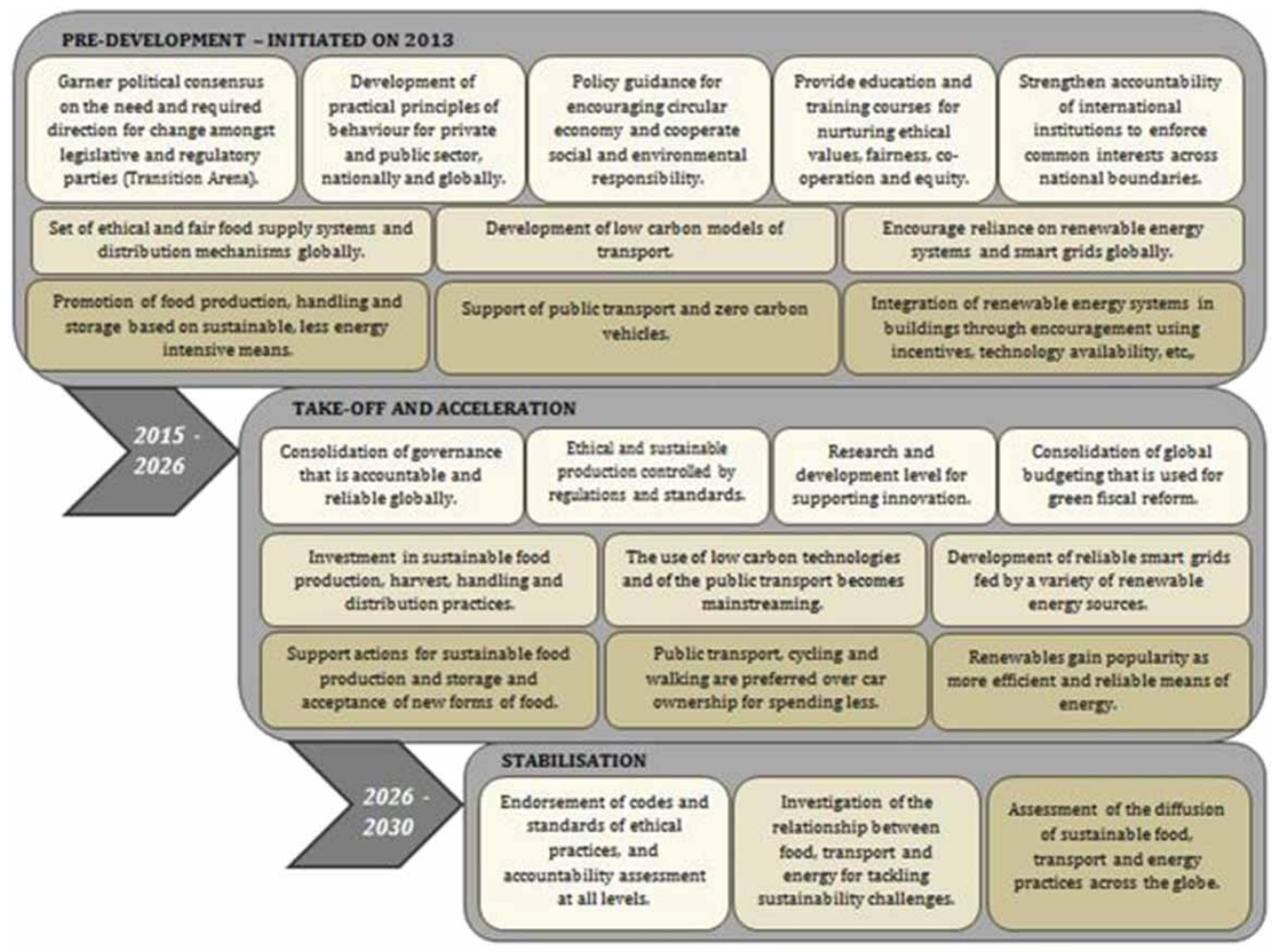

Governance $\square$

Structure $\square$

Practices $\square$

Figure 3. Framework of action for the One Ethical World pathway. 


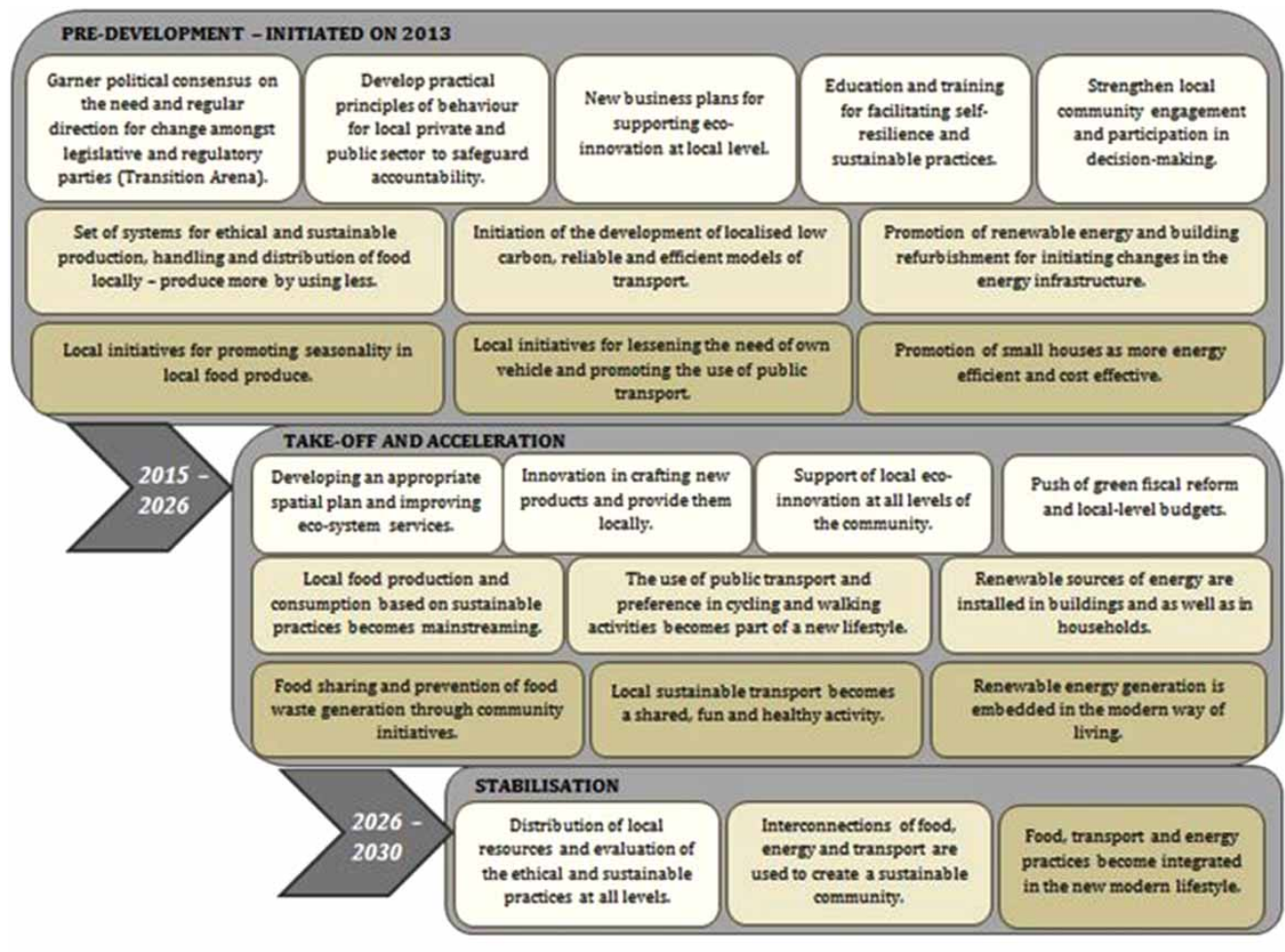

\section{Governance $\square \quad$ Structure $\square \quad$ Practices $\square$}

Figure 4. Framework of action for the Local Community pathway.

suitable electricity grid will inevitably take longer than five years to complete. For this reason, Take-off and Acceleration are presented as one phase encompassing a 10-year time period for the transition of the pathway's development towards a sustainable, low-carbon Europe.

\section{The frameworks of action}

Each cluster is described by a key activity for each pathway, based on the structural framework and taking into consideration the insights and reflections from the workshop reports. This gave rise to each pathway's framework of actions presented below. The first (Figure 3) is the framework of actions for One Ethical World.

This framework is described according to the principles of fair trade, accountability and transparency, thus allowing global initiatives to be undertaken impartially. The establishment of a multi-stakeholder Transition Platform with a consultancy and strategic character is fundamental and will be accountable for making decisions, exchanging ideas and developing new business models. This should ensure the enforcement of common interests across national boundaries and safeguard ethical standards, which will be strengthened through education and training that focuses on nurturing global understanding and responsibility.

Changes in food, transport and energy sectors will occur through the growth of new or improved food supply chains, the elimination of unsuitable products, harnessing natural resources for the generation of energy, ensuring its equal distribution and consumption, retrofitting existing housing where possible, closing fossil fuel power stations, controlling carbon emissions 


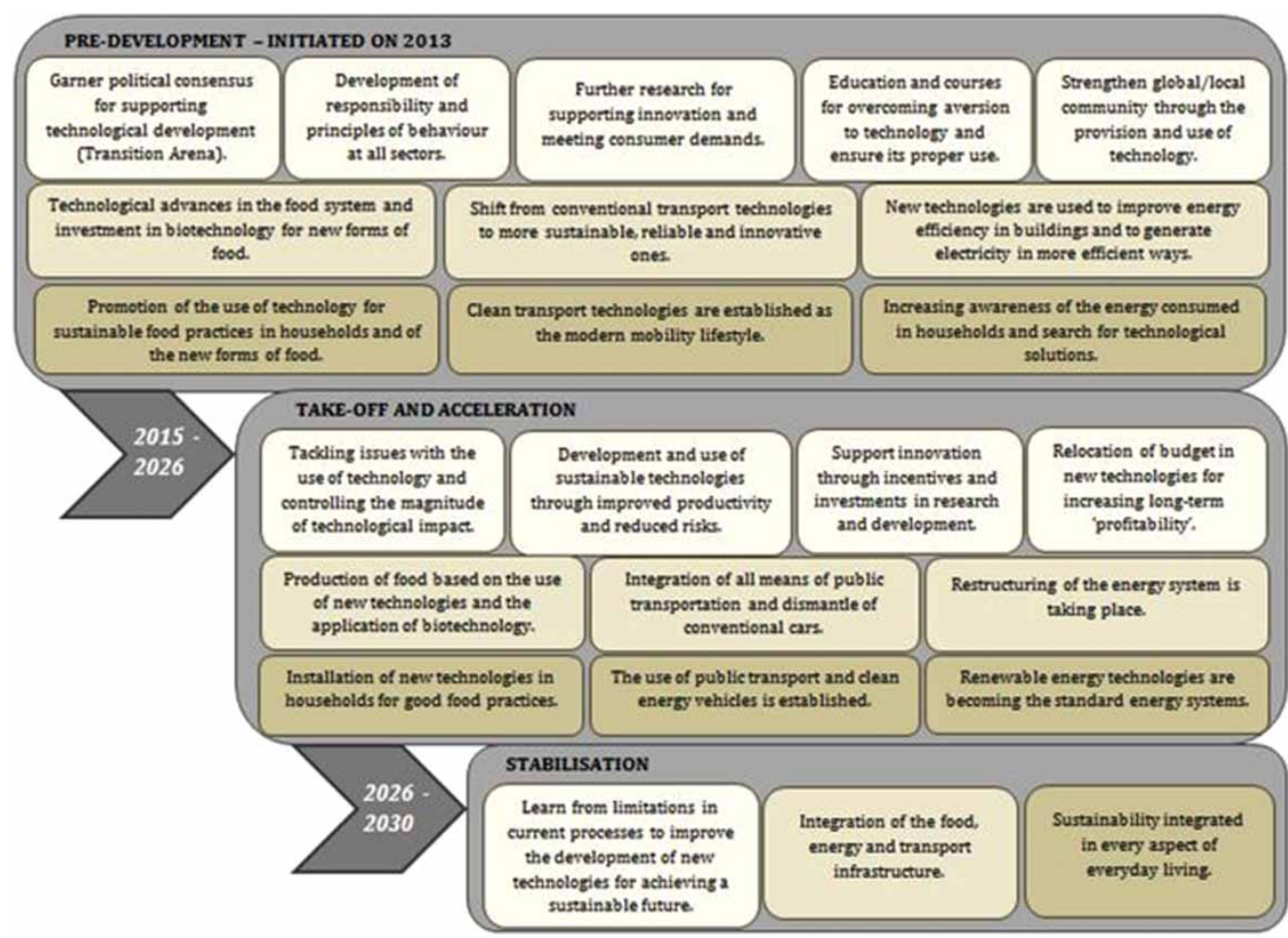

Governance $\square$

Structure $\square$

Practices $\square$

Figure 5. Framework of action for the $i$-Tech pathway.

associated with transport, regulating car ownership, the completion of an integrated, affordable and reliable transport system, and many more such initiatives. These changes require only a few common factors: equity, ethical responsibility and security.

All major improvements will be revisited, reviewed and re-proposed through the cooperation of international institutions, people and networks that are committed to the needs of different social and cultural groups with common goals for the common good. New spatial plans will be devised and green fiscal reforms will be developed, with the discontinuance of any unsustainable activities. The benefits arising from new practices will be widely demonstrated to encourage fast-paced changes across nations.

In order for these events to occur, however, it will be necessary to change the cultural and social features of all nations to enable the move towards more sustainable lifestyles and, hopefully, towards One Ethical World. It will also require strong political will and substantial social and financial investment.

In contrast to the framework of actions for One Ethical World, that of the Local Community pathway, presented in Figure 4, advocates a number of changes based on the principles of Localism. Governance, food, energy, transport infrastructure and practices will all be based on a localised control system that will enable consumers to become more sustainable. At the governance level, actions will necessitate the involvement of citizens in the decision-making process, which will be essential for bringing about changes, because if citizens understand why the changes are necessary, they will be more willing to embrace them in their lives. 
A locally based food system will help to provide consumers with seasonal food produced locally and available at prices that reflect the real cost of production based on less intensive production processes and shorter transportation distances. These food production and distribution practices will result in a decrease in carbon emissions. Moreover, consumer dependence on seasonal food will make them more appreciative and less inclined to waste it. An overall assessment of the food produced, based on supply and demand, will be carried out with the selection of specific types of food and products that guarantee nutritional, healthy diets and lifestyles.

Local transport will steadily become more efficient as cycling routes are constructed and pedestrian pathways are improved to support these activities within the community, especially over short distances. Public transportation will also be improved, both in terms of cost and reliability, to increase take-up and gain the trust of customers, thereby becoming well established in the community.

Initiatives for local energy generation will gather pace to bring the community closer, rendering it self-reliant and sustainable. The establishment of high efficiency standards for households (insulation, waste management, water capture and usage) will promote awareness and the use of new technologies for becoming more water and energy efficient.

The establishment of regional circular economies applied to value chains of products and services will bring growth to the community, which will become, for the most part, self-sustaining and resilient. Benefits gained from the new practices will incentivise people to continue their efforts in the same direction and support the domino effect in changing lifestyles and food habits.

Finally, the framework of actions for the $i$-Tech pathway (Figure 5) highlights the necessity of taking dormant, though suitable, technology and applying it practically and beneficially to promote sustainability. Technology innovation, which is equally important to development, is also clearly stated in the actions involved in this framework. Regulation will keep pace with technological advancements to ensure that they are readily deployed for industrial, business or household-related practices. An increase in consumer confidence in new technologies will be decisive for the promotion, acceptance and diffusion of new, more sustainable technologies in society.

Integration of food, energy and transport, vital for the consolidation of sustainable processes in all three systems, necessitates the use of advanced and sustainable technologies and the continual innovation of new ones. These include devices for changing food supply chains and providing new sources of energy; harnessing resources in efficient and reliable ways; and producing information technology to make people aware of the impacts of their actions, habits and practices. Strategies to promote such technological advancements will involve investing in companies that work in these areas. This being said, research and development constitute an essential part of the $i$ Tech pathway towards a sustainable future.

\section{The evaluation of the pathways}

Pathways developed in CRISP were compared to six pathways developed in the context of the 2050 Pathways Analysis report by the Department of Energy and Climate Change (DECC, 2010) aimed at helping the UK reduce its greenhouse gas (GHG) emissions by at least $80 \%$ by 2050, relative to 1990 levels - the legally binding national target set out in the Climate Change Act of 2008. For the development of these pathways, existing work, as well as input from a large number of experts from businesses, non-governmental organisations and technical fields, together with the opinions of academics, and several hundred stakeholders who took part in workshops and in-depth discussions, were combined to generate a diverse range of views that were then used for the pathway development (DECC, 2010).

The six pathways developed considered some of the choices and trade-offs that will have to be made over the next 40 years in order to transform the UK's economy and ensure secure, low- 
carbon energy supplies by 2050. They took into consideration: (1) all parts of the economy; (2) emissions from all different sources such as the supply and use of energy, agriculture, waste, industrial processes, carbon capture technologies, land use, land use change and forestry; and (3) possible drivers and constraints that affect different sectors, such as economic growth, population growth, technical potential, roll-out rates, land availability and ecological sensitivity, looking at what was thought to be physically and technically possible for each sector (DECC, 2010).

The main factors considered across the six pathways are in line with the key changes endorsed by the CRISP pathways. This indicates that the CRISP pathways are well focused, and that the recommendations derived from them can be determining factors in the development of other pathways. These factors are:

- Behavioural and lifestyle changes

- Technological improvements and innovation

- Different fuel choices

- Structural change

- Local approaches to policy design and development.

In fact, these factors are very similar to the clusters outlined above and many individual building blocks or items in the "To do lists" were very similar or identical, particularly the actions related to the changes recommended in the transport and energy sectors. These are presented in Table 2.

Table 2. Comparison of specific actions proposed in the 2050 pathways and the CRISP 2030 pathways.

2050 pathways $^{\text {a }}$ CRISP pathways

Increases in renewable energy (e.g. by harnessing Developing integrated global renewable energy natural resources).

Better insulation in buildings and households.

Reducing household energy demand by replacing all lights with LEDs and using more efficient appliances.

Greater efficiencies in the transport sector (e.g. hybrids, fuel cell cars, electrified rail).

Development and penetration of low-carbon technologies.

Energy provision from domestic agricultural production.

Shift from freight to rail and water transport.

Development and penetration of low-carbon technologies.

Successful deployment of new energy efficient technologies.

Encouraging people through the right incentives. system.

Regulation to facilitate home energy generation and insulation.

Refurbishment of housing to reduce energy consumption and installation of the latest energy generation and conversion technologies.

Internationally integrated low-carbon transport system and focus on the development of low-carbon modes of transport.

Development of local smart grid.

Community planning that integrates local sustainable food and energy.

The establishment of teleworking and telecommunications.

Development of biofuels and fuel cells for transport, and technological updating of neighbourhoods.

Local and national government support for not only developing low-carbon technology for sustainable living, but facilitating its use.

Making local production and consumption pay (e.g. incentives).

${ }^{\mathrm{a}} \mathrm{DECC}(2010)$. 
The similarities observed in Table 2 indicate the success of the novel methodological approach adopted for developing the CRISP pathways, which involved not only experts but also laypeople. This finding is significant since it provides strong evidence of the ability of young people to recommend changes similar to those recommended by experts. This is further supported by comparing the workshop results for both experts and laypeople, which shared many similarities in structure and/or outcome. However, a considerable difference observed between the two was that laypeople's workshops were noticeably devoid of technical knowledge on energy, food and household systems, infrastructure specifications and/or factors that could shape innovation towards or away from the visions, whereas the workshops of experts were coherent and founded on strong prior knowledge of the associated technical and practical aspects. Yet in some cases, that prior knowledge proved to be an obstacle to experts when helping to develop pathways that they personally did not favour or accept as being viable.

Technical knowledge is often vital for making pathways viable, although it does not define the pathway's structure, and consequently the incorporation and interpretation of experts' insights, ideas and knowledge are indispensable. CRISP has shown that this can be done, and that it should be done, but precise recommendations on which is the best methodology to adopt cannot be made, given the scope of CRISP.

\section{Discussion}

The pathways developed in CRISP constitute important tools for change because they are not limited to a specific area of concern, nor do they attempt to provide a detailed plan of action, but span across three key areas, making recommendations on things that need to be changed in order to make the transition to a sustainable, low-carbon Europe. It is no easy task to achieve, and during the development of the pathways many efforts were made to put forward perspectives from the point of view of participants and facilitators to ensure that all aspects had been taken into account. It should be emphasised, however, that the complexities and complications involved in each action recommended in the pathways were not examined in this project since this would require thorough and extensive research and an in-depth analysis of the actions recommended.

In addition, the rather short timeframe selected by CRISP implies a transition to a radically different set of practices, policies and ethical values in little more than 15 years, which should be viewed as an important context variable for the evaluation of the pathways. The future is unpredictable and those aspects of the future that are predictable are not necessarily desirable, and therefore none of the pathways developed within CRISP should be considered conclusive and determinant. They are maps with recommended routes on how to make transitions to a sustainable, low-carbon Europe by 2030. Moreover, although the recommendations made involve specific changes to policy, economy, infrastructure, practices and culture, the actual rate and scale of these changes is not specified.

The frameworks of action that describe the pathways follow the same pattern and timeframe. This timeframe makes the changes more or less urgent and therefore challenging. In a way, pathways can be transformed over time, indicating the political and social willingness to change. Nevertheless, pathways should be continuously assessed and evaluated on the grounds of clarity, depth of analysis, the transferability of actions and their applicability to diverse stakeholders, in order to deal with complexities that surface in the interactions between different spheres and levels, and societal/public/political support. This would enable the pathways to be successfully followed towards sustainability.

A closer look at the pathways' frameworks of actions reveals that some changes will be inevitable when striving to achieve the future visions, and that some of these changes will be found to be common within the visions. These changes need to be initiated in order to provide a strong 
foundation for individual visions. Consequently, and to follow the MLP (Geels \& Kemp, 2007), we must give promising and suitable bottom-up initiatives the chance to grow out of their niche. It is important to create a transition arena that will bring together stakeholders and allow them to communicate effectively to provide strategic plans for starting up such initiatives. The role of the transition arena, however, is not solely to encourage communication between stakeholders, but also to address changes at all levels of society including governance, infrastructure, practices and culture.

When introducing and implementing changes, stakeholders must ensure that peoples' rights, needs and personal interests are not compromised. The process of implementation must be transparent so that people can understand the motives for such changes, thus increasing the likelihood of their acceptance. Transparency in business and governance is also necessary to secure accountability, a prerequisite if changes are to be embedded in society. It is also evident from the pathways' frameworks of action that transition to a sustainable future relies on the development of new business models and innovation, which evolve throughout time and the transition processes, as well as on the development of individual skills and engagement with mechanisms that structure societal change. This creates a strong basis for sustainable development that will allow changes to take effect in different lifestyles.

The evaluation of the pathways conducted by comparing them to other pathways developed by experts, specialists and stakeholders showed that the novel methodological approach adopted by CRISP produced equally sound and coherent results. In other words, it is possible for laypeople to individuate their desired future and to develop attractive visions of low-carbon sustainable lifestyles, as well as radical yet feasible pathways for getting there. The involvement of laypeople, especially younger ones, in the process of developing sustainable, viable and feasible pathways is essential. Furthermore, if laypeople (and pupils) can produce viable pathways that are comparable to those of experts, one can conclude that pathways are not the exclusive domain of experts or those with technical and theoretical knowledge, but the responsibility of all and can be developed with top-down or bottom-up approaches. Technical knowledge and leadership at both national and regional levels are of course required for the development of effective pathways, but they are not necessarily the drivers of pathway design, thus supporting the case for bottom-up participatory drivers towards radical change.

Finally, there is a difference between possible futures and likely futures, as experience with many other third-generation scenarios has shown. The most likely future is probably a combination of different pathways, in as much as the most likely end state is a combination of different visions. The "logic of change" is a persistent element in this. Therefore, the "likely" future is probably a blend of pathways, which would arguably be a more significant development than separate trajectories towards different futures. The involvement of society is the start and the driver of profound changes. Dialogues must be kept open and there must be active communication regarding the visions and pathways throughout the process. In addition, when considering the rapid pace of change, something that may seem unrealistic today may actually be achievable tomorrow. The scope and acceptability of change is often misunderstood and underestimated.

\section{Conclusions}

The main conclusions derived from this paper are the following:

- The methodological approach adopted by CRISP was novel given that it involved the participation of young people in the development of visions and the pathways towards them. 
- The steps taken for the development and synthesis of the pathways were based on backcasting theories and MLP, and provided a well-structured route for developing transition pathways.

- The pathways' frameworks of action can be used as a map for sustainability, enabling the tracking of necessary changes that must be implemented in order to achieve the desired future visions.

- The way pathways have been developed up until now - using experts, specialists and technically competent advisors - is only one way of developing such pathways.

- A technical background is undoubtedly vital when devising pathways and there must always be the involvement of some experts in this procedure.

- Evidently, it is possible for young people and members of the general public to make substantive, constructive and meaningful contributions to the design of pathways to their desired future.

\section{Funding}

This paper was supported by the European Commission under the Environment (as well as climate change) Theme of the 7th Framework Programme for Research and Technological Development [Project Number 265310].

\section{References}

Börjeson, L., Höjer, M., Dreborg, K. H., Ekvall, T., \& Finnvedena, G. (2006). Scenario types and techniques: Towards a user's guide. Futures, 38, 723-739.

Carlsson-Kanyama, A., Dreborg, K. H., Moll, H. C., \& Padovan, D. (2008). Participative backcasting: A tool for involving stakeholders in local sustainability planning. Futures, 40, 34-46.

Chenoweth, J., \& Wehrmeyer, W. (2006). Scenario development for 2050 for the Israeli/Palestinian water sector. Population and Environment, 27, 245-261.

DECC. (2010). 2050 pathways analysis. London: Crown Copyright.

Eames, M., \& McDowall, W. (2010). Sustainability, foresight and contested futures: Exploring visions and pathways in the transition to a hydrogen economy. Technology Analysis and Strategic Management, 22, 671-692.

Foxon, T. J., Hammond, G. P., \& Pearson, P. J. G. (2010). Developing transition pathways for a low carbon electricity system in the UK. Technological Forecasting and Social Change, 77, 1203-1213.

Geels, F. W. (2002). Technological transitions as evolutionary reconfiguration processes: A multi-level perspective and a case-study. Research Policy, 31, 1257-1274.

Geels, F. W. (2005). Processes and patterns in transitions and system innovations: Refining the co-evolutionary multi-level perspective. Technological Forecasting and Social Change, 72, 681-696.

Geels, F. W. (2006). The hygienic transition from cesspools to sewer systems (1840-1930): The dynamics of regime transformation. Research Policy, 35, 1069-1082.

Geels, F. W., \& Kemp, R. (2007). Dynamics in socio-technical systems: Typology of change processes and contrasting case studies. Technology in Society, 29, 441-455.

Höjer, M., \& Mattsson, L.-G. (2000). Determinism and backcasting in future studies. Futures, 32, 613-634.

Holmberg, J. (1998). Backcasting: A natural step in operationalising sustainable development. Greener Management International, 23, 30-51.

Kok, K., Van Vliet, M., Bärlund, I., Dubel, A., \& Sendzimir, J. (2011). Combining participative backcasting and exploratory scenario development: Experiences from the SCENES project. Technological Forecasting and Social Change, 78, 835-851.

Lachman, D. A. (2013). A survey and review of approaches to study transitions. Energy Policy, 58, 269-276.

Mander, S. L., Bows, A., Anderson, K. L., Shackley, S., Agnolucci, P., \& Ekins, P. (2008). The Tyndall decarbonisation scenarios - Part I: Development of a backcasting methodology with stakeholder participation. Energy Policy, 36, 3754-3763.

Quist, J. (2007). Backcasting for a sustainable future: The impact after 10 years. Delft, the Netherlands: Eburon Academic. 
Quist, J., \& Vergragt, P. (2006). Past and future of backcasting: The shift to stakeholder participation and a proposal for a methodological framework. Futures, 38, 1027-1045.

Robinson, J. B. (1988). Unlearning and backcasting: Rethinking some of the questions we ask about the future. Technological Forecasting and Social Change, 33, 325-338.

Robinson, J. B. (2003). Future subjunctive: Backcasting as social learning. Futures, 35, 839-856.

Rotmans, J., Kemp, R., \& van Asselt, M. (2001). More evolution than revolution: Transition management in public policy. Foresight, 3, 15-31.

Smith, A., \& Stirling, A. (2010). The politics of social-ecological resilience and sustainable socio-technical transitions. Ecology and Society, 15, 11-24.

Van De Kerkhof, M., \& Wieczorek, A. (2005). Learning and stakeholder participation in transition processes towards sustainability: Methodological considerations. Technological Forecasting and Social Change, $72,733-747$.

Van Den Ende, J., \& Kemp, R. (1999). Technological transformations in history: How the computer regime grew out of existing computing regimes. Research Policy, 28, 833-851.

Wehrmeyer, W., Fudge, S., Stasiškienė, Z., Van De Lindt, M., Emmert, S., Kondili, E., \& Papathanasopoulou, E. (2012, May 2-4). Designing effective visioning workshops. Presented at the European Round Table on Sustainable Consumption and Production (ERSCP) Conference, Bregenz.

Wehrmeyer, W., Iacovidou, E., \& Coke, A. (2013, October 7-8). Transition pathways towards a sustainable, low carbon europe developed by pupils and professionals across 6 EU countries. Proceedings of the InContext Scientific Conference on Pathways, Scenarios and Backcasting for Sustainable and Low Carbon Lifestyles: Comparing Methods, Cases and Results, Rotterdam. 